\title{
Managing the COVID-19 Pandemic: Research Strategies Based on the Evolutionary and Molecular Characteristics of Coronaviruses
}

\author{
Sabhiya Majid ${ }^{1}$ (D) Rabia Farooq ${ }^{1,2} \cdot$ Mosin S. Khan $^{1} \cdot$ Samia Rashid $^{3} \cdot$ Showkat A. Bhat $^{4} \cdot$ Hilal A. Wani $^{1} \cdot$ \\ Waseem Qureshi ${ }^{5}$
}

Accepted: 11 August 2020 / Published online: 25 August 2020

(C) Springer Nature Switzerland AG 2020

\begin{abstract}
Coronavirus disease 2019 (COVID-19), an ongoing global health emergency, is a highly transmittable and pathogenic viral infection caused by severe acute respiratory syndrome coronavirus 2 (SARS-CoV-2). Emerging in Wuhan, China, in December 2019 , it spread widely across the world causing panic - worst ever economic depression is visibly predictable. Coronaviruses (CoVs) have emerged as a major public health concern having caused three zoonotic outbreaks; severe acute respiratory syndrome-CoV (SARS-CoV) in 2002-2003, Middle East respiratory syndrome-CoV (MERS-CoV) in 2012, and currently this devastating COVID-19. Research strategies focused on understanding the evolutionary origin, transmission, and molecular basis of SARS-CoV-2 and its pathogenesis need to be urgently formulated to manage the current and possible future coronaviral outbreaks. Current response to the COVID-19 outbreak has been largely limited to monitoring/containment. Although frantic global efforts for developing safe and effective prophylactic and therapeutic agents are on, no licensed antiviral treatment or vaccine exists till date. In this review, research strategies for coping with COVID-19 based on evolutionary and molecular aspects of coronaviruses have been proposed.
\end{abstract}

Keywords Coronavirus $\cdot$ COVID-19 $\cdot$ SARS-CoV-2 $\cdot$ SARS-CoV $\cdot$ MERS-CoV

\section{Introduction}

Coronaviruses (CoVs) are spherical RNA viruses, deriving name from Latin word "corona" or crown as they appear like a royal crown under the electron microscope due to

Rabia Farooq and Mosin S. Khan have contributed equally as second authors

Sabhiya Majid

sabuumajid@gmail.com

1 Department of Biochemistry, Government Medical College Srinagar and Associated Hospitals, Srinagar, J\&K 190010, India

2 Department of Basic Medical Sciences, University of Bisha, Bisha 67714, Saudi Arabia

3 Department of Medicine, Government Medical College Srinagar and Associated Hospitals, Srinagar, J\&K 190010, India

4 Department of Biochemistry, Government Medical College Doda, Doda, J\&K 182202, India

5 Registrar Academics, Government Medical College Srinagar, Srinagar, J\&K 190010, India characteristic spike projections on their spherical surface. CoVs belong to family Coronaviridae within order Nidovirales, which further has two subfamilies: Orthocoronavirinae and Torovirinae. Subfamily Orthocoronavirinae encompasses four genera: alpha coronavirus, beta coronavirus, gamma coronavirus, and delta coronavirus [1]. Beta coronaviruses are a subgroup of the coronavirus family, large enveloped positive-sense singlestranded RNA (+ssRNA) viruses able to infect a wide variety of mammals and avian species, causing mainly respiratory or enteric diseases [2]. Discovered long back in 1960s, HCoV$229 \mathrm{E}$ and HCoV-OC43 were known to cause common cold in humans. To date, seven beta coronaviruses are known to cause human disease - the prevalent strains, HCoV 229E, HKU1, NL63, and OC43, typically cause mild infections of the upper respiratory tract in humans [3-5]. However, scenario has altered in the past two decades with CoVs becoming a major public health concern as three strains, SARS-CoV [6, 7], MERS-CoV [8, 9], and the newly identified SARS-CoV-2, are associated with serious respiratory diseases and have led to severe zoonotic outbreaks [10-12]. The SARS-CoV pandemic initiated in Guangdong Province, China, in 2002. The 
infected patients exhibited pneumonia symptoms with a diffused alveolar injury which lead to acute respiratory distress syndrome (ARDS); the disease quickly spread worldwide causing serious illnesses and nearly 800 deaths in 2002$2003[13,14]$. MERS-CoV epidemic took place in 2012 [8, 9]. In both cases, the infected patients manifested severe acute pneumonia, but while SARS-CoV infected mainly the lower respiratory tract, MERS-CoV caused more pronounced gastrointestinal symptoms, often associated with kidney failure $[15,16]$. The World Health Organization (WHO) has reported a total number of 2519 MERS-CoV cases with 866 associated deaths from 2012 to 31 January 2020 [17].

SARS-CoV-2 and the COVID-19 Pandemic Currently, the novel coronavirus, SARS-CoV-2 alternatively termed $2019 \mathrm{nCoV}$, has caused panic with WHO declaring it as a global health emergency on 30 January 2020 [18]. It was initially identified in the city of Wuhan, China, in December 2019; patients presented with severe viral pneumonia and respiratory illness. The number of cases has been mounting since then to whopping figure of around six and half million globally [19-22]. The disease caused by SARS-CoV-2 has been named COVID-19, a highly transmittable and pathogenic respiratory infection, which has become a public health emergency of international concern as no clinically approved antiviral drug or vaccine is available - though few broad spectrum antiviral drugs and drug combinations in clinical trials have resulted in clinical recovery [23-27]. Convalescent plasma (CP) therapy has recently been shown to be well tolerated, and severe COVID-19 cases could potentially improve the clinical outcomes by neutralizing viremia [28]. Transmission is via respiratory droplets or aerosols on exposure to coughing, sneezing, and close contact with an infected person [29]. Social distancing, face masks, and frequent hand sanitization are recommended preventive measures. Personal protective gear as recommended is to be used by healthcare workers for their safety. Containing the outbreak before it can spread is the best way to prevent pandemics. Border closures, screening at airports, and checkpoints-classical measures implemented in pandemics - can reduce spread of the virus but will not be a fool-proof strategy [30, 31]. Millions of people travel every day from one country to another; a disease originating in one country can rapidly spread to other countries regardless of distances between them. This is particularly visible in the rapid spread of COVID-19, which affected almost every country in the world within 3 months of the first reported case. Information technology is playing its own role with numerous apps coming up, purportedly helping cope with awareness, management, and controlling spread of this disease-like "Aarogya setu App" in India.

This disease can remain asymptomatic during around 14 days incubation period of SARS-CoV-2. The SARS and MERS CoVs evade immune responses during longer incubation periods. The spectrum of COVID-19 disease is broad - most commonly reported symptoms of are fever, myalgia or fatigue, dry cough, and dyspnea. Around $80 \%$ of infections are mild, resolving within a week without any specific treatment or hospitalization. Amongst hospitalized cases, pneumonia, sepsis, respiratory failure, and ARDS are frequently encountered complications, and in severe cases, progressive respiratory failure can be fatal [32-34]. Overproduction of early response pro-inflammatory cytokines can result in cytokine storm leading to vascular hyperpermeability, reduced anticoagulant concentration, impaired anticoagulant-procoagulant balance predisposing to development of microthrombosis, disseminated vascular coagulation, and multi-organ failure [35]. This is evidenced in severe COVID-19 pneumonia where raised d-dimer is a poor prognostic feature and disseminated intravascular coagulation is common in non-survivors [36].

As clinical manifestations of COVID-19 range from mild to moderate, more systematic symptoms and severe radiological abnormalities are seen in older patients [37]. Children and younger adults can remain as asymptomatic carriers [38-40]. The possibility for gastrointestinal involvement in SARSCoV-2 infection and feco-oral transmission has been suggested [41]. WHO has estimated overall mortality rate of $3.7 \%$ in spite of the significant infectivity rate, majority deaths typically occurring amongst elderly patients, patients having multiple comorbidities, and immune compromised population [42].

\section{Evolutionary Origin and Transmission of Coronaviruses}

The COVID-19 epidemic has reached worldwide resonance; global efforts are being undertaken to characterize the molecular features and evolutionary origins of this virus. CoVs are typically harboured in mammals and birds - being common in camels, cattle, cats, bats, and other animals [43-45]. Alpha and beta coronaviruses circulate in mammals, including bats. Gamma coronaviruses mostly infect avian species and a few mammalian species, whereas delta coronaviruses infect birds and mammals [46, 47]. Animal CoVs are known to cause important diseases in animals and are responsible for economic losses in domestic animals or bird. Although rare, zoonotic events do occur wherein animal CoVs acquire the ability to infect humans and further spread through human-to-human transmission $[48,49]$.

Studies have shown that bats harbour $\mathrm{CoV}$ s that are ancestral to SARS-CoV which have been circulating in bats for a long time before genetically changing and jumping to humans [50]. Rhinolophus bats were found to have anti-SARS-CoV antibodies suggesting bats as a source of viral replication [51]. Further, studies have revealed that palm civets and raccoon 
dogs, of Chinese local food markets, harbour SARS-related CoVs (SARSr-CoVs) suggesting that they could be key reservoir of infection and may be secondary hosts. This detection of SARSr-CoVs in bats and small animals in retail markets may indicate an interspecies transmission from bats to small animals and finally to humans [52]. In 2001, samples from the healthy persons of Hong Kong on molecular assessment showed $2.5 \%$ frequency rate of antibodies against SARS$\mathrm{CoV}$, indicating that SARS-CoV might have been circulating in humans before causing the outbreak in 2003 [53]. MERS$\mathrm{CoV}$ reportedly has camels as a zoonotic source or primary host [44]. In a recent study, MERS-CoV was also detected in Pipistrellus and Perimyotisbats, favouring bats as key host and transmitting medium of this virus [54].

Metagenomics analysis of phylogenetic relationships between SARS-CoV-2, SARS-CoV, bat SARS r-CoVs, and Bat $\mathrm{CoV}$ revealed that SARS-CoV-2 genome $(\sim 29.9 \mathrm{~kb})$ shares $79.5 \%$ sequence identity with SARS-CoV. Again, close phylogenetic relationship between SARS-CoV-2 and a bat $\mathrm{CoV}, 96 \%$ identical at whole genome level, points to bat origin of SARS-CoV-2 and bats as probable "key reservoirs" [55]. Overall, these studies highlight bats as carriers of viruses with zoonotic and devastating potential. However, intermediate source of origin and transfer to humans is not known; further studies are needed to determine whether the virus was transmitted to humans by an intermediate host. Nevertheless, rapid human-to-human transfer has been widely confirmed, already reported from more than 100 countries in the world $[56,57]$.

\section{Research Strategies to Limit Zoonotic Transmission and Prevent Future Coronaviral Outbreaks}

Coronaviruses will continue to infect multiple species and cell types, including humans due to their ability to recombine and mutate. The source and spread of these CoVs necessitate to be evidently firmed; urgency finance for investigation on systematic basis of their spread and their pools is required to frame preventive plans to hold and regulate such outbreaks. In the phylogenetic connection between extremely pathogenic $\mathrm{CoVs}$, their transitional zoonotic source requires to be vigorously studied. Role of variations in human doings, biomes, and environment in leading to such pandemics requires to be studied as the changes in pathogen types, disease burden, and distribution have arisen largely due to human activity. In the last century, there was a reduced burden of infectious diseases due to improved nutrition, better hygiene, and use of vaccines and antimicrobials. However, in recent decades, there is an upsurge of disease emergence and propensity to pandemics much due to swelling global travel and trade, increasing human and livestock populations. Viruses have broad range of hosts and are emerging pathogens [58].
In 2016, the United Nations Environment Programme (UNEP) warned that zoonotic diseases are related to the health of ecosystems. Zoonoses are opportunistic and increase with changes in animal or human hosts, environment, or pathogen itself. Pathogens have passed between animals and humans in the last century due to reduction in ecosystems by human intervention and population growth. Humans have encroached into animal habitats and disturbed natural buffer zones between animals and humans leading to emergence of zoonosis. Livestock serves as a bridge between wildlife and human infections and forms a part of wildlife-livestock-human interface. Consumer demand for livestock has increased due to economic growth leading to rigorous livestock farming near and around cities, thereby, expanding chances of zoonotic diseases. In addition, natural source of disease resistance is genetic diversity but "intensive livestock rearing" often produces genetic similarities within herds and flocks, making them susceptible to pathogen spillover from wild animals. Consumption of wild animals in wet markets can also facilitate animal to human transmission. Frequent climate change tells upon the survival of microbes in the environment, suggesting the more frequency of pandemics due to rapid change in climate [59].

Thus, if we need to stop such pandemics in the future, we need to focus on the influence of human activities on ecosystems. Experiments on monitoring of human and wildlife health will improve understanding and preparedness for potential pandemics. It invites for collaborative, trans-disciplinary, and international efforts as summarized by the "One Health Approach"- a concept of combining human, animal, and environmental components to address global health challenges having ecological interdependence. "One Health Approach" wherever adopted is seen to have significant impacts on control of infectious diseases [60]. Ultimately, "If we have a robust plan for protecting nature, nature will protect humanity".

Last but not the least, strategies to curb the transmission of virus should be put in place in a more stringent way. The correct use of personal protective equipment (PPE) and regular and thorough hand hygiene are key measures in the prevention and control against infection through contact transmission, droplet transmission, and airborne virus particles. In addition, maintaining a constant and regular supply of drugs is indispensable during the pandemic. Healthcare professionals are at three times higher risk than common individuals so their body temperature, nucleic acid, and specific antibodies for COVID19 should be monitored regularly. During pandemic, psychological illness is rampant so individuals especially healthcare workers should be evaluated for psychological illness, if any. Our understanding of the virus deepens, and with the constant improvement of diagnosis, treatment, and strategies for prevention and control, healthcare 
professionals should continue to actively collect and improve their services based on the latest information [61].

\section{Molecular Aspects: Genomics, Proteomics, and Transcriptomics of Coronaviruses}

A crucial need to counteract the COVID-19 pandemic has arisen; no specific drug or vaccine is available as yet. For effective therapeutics and vaccine development elucidation of genetic features and molecular constituents of CoVs including SARS-CoV-2, unravelling the mechanisms of infection, molecular basis of virus-host interaction, its regulation, and host responses is needed. Global efforts are being undertaken-biotechnological, molecular, and bioinformatic advances have been helpful in making available details related to the genomics and proteomics of these CoVs, especially SARSCoV-2 in a very short time [62].

\section{Genome Organization, Replication, and Transcription of CoVs}

The CoVs are $\sim 65-125 \mathrm{~nm}$ in diameter, containing singlestranded RNA ranging from 26 to $32 \mathrm{kbs}$ in length as nucleic material, being enveloped in lipid bilayer derived from the host cell membrane. The structural together with few nonstructural proteins (nsps) are coded within the $3^{\prime}$ end of the viral genome, whereas the $5^{\prime}$ two-thirds of the genome codes for nsps that are important in viral replication, including the RNA-dependent RNA polymerase (RdRP) [63, 64] .

RNA of CoVs codes for four major structural proteins involved in its replication as well, termed as spike (S), membrane (M), envelope (E), and nucleocapsid (N) proteins. Some beta coronaviruses also code for protein hemagglutinin esterase (HE). The $\mathrm{S}, \mathrm{M}$, and $\mathrm{E}$ proteins lie in the viral envelope. The $\mathrm{S}$ protein is heavily glycosylated forming homotrimeric spikes on the surface of the viral particle required for binding and entry into host cells. Amongst the four, M protein is the most abundant and important protein giving the virion primarily its shape; besides, it interacts with other structural proteins to perform various functions. Interaction of $\mathrm{S}$ proteins with $\mathrm{M}$ proteins is needed for its incorporation into new virions [65-67]. In the same way, M protein along with the smallest one $\mathrm{E}$ protein which is found in small quantities is involved in virus assembly, forming of mature viral envelopes, and release of viral particles from host cells. E protein is mostly expressed in the infected cell; it is important for production and maturation of the virus, and its interaction with PSD95/DLG/ZO$1(\mathrm{PDZ})$ proteins involved in host cell processes is important for viral infection. The $\mathrm{N}$ protein is located in the core of the viral particle forming the nucleocapsid of viral RNA and is involved in replication $[68,69]$.
Generally, the transcription and replication of CoVs take place in the host cell cytoplasm following viral entry. Spike proteins of the virus bind with the host receptor, structural changes occur followed by endocytosis, which is $\mathrm{pH}$ dependent [70], and the virus releases its RNA inside the host cell cytoplasm. Translation of the $5^{\prime}$ end of viral RNA produces the RdRP, which uses viral RNA as a template to generate series of virus-specific mRNAs or sub-genomic mRNAs from sub-genomic negative strand intermediates. Translation of sub-genomic mRNAs leads to production of structural and nonstructural viral proteins; they share the same $3^{\prime}$ ends and the same leader sequence of 70-90 nucleotides at their $5^{\prime}$ ends [71]. Once sufficient, structural proteins and genomic viral RNA are synthesized; viral assembly and budding occur in smooth-walled vesicles in the endoplasmic reticulum-Golgi intermediate compartment (ERGIC) [72].

RNA of coronavirus is polycistronic containing approximately seven genes: $5^{\prime}$ region mainly contains large replicase gene for replication and transcription process, and the $3^{\prime}$ region contains nonessential accessory proteins expressed from sub-genomic mRNAs [73]. The large replicase gene at 5' end encodes replication-transcription complexes (RTCs) amongst CoVs which comprise of two overlapping open reading frames (ORFs), ORF1a and ORF1b. Translation of these ORFs results in two very large polyproteins, polyprotein 1a (PP1A) and polyprotein 1ab (PP1AB), further leading to formation of nonstructural proteins by co- and post-translational modifications by various proteinases. ORF1b encodes enzymes which are needed in RNA replication and its transcription. All CoVs contain specific genes in ORF1 downstream regions that encode proteins for viral replication, nucleocapsid, and spike formation [74, 75]. CoVs contain doublemembrane vesicles (DMVs) which are attached with RTCs; these DMVs are derived from network of modified ER membranes, also referred to as convoluted membranes (CMs) [76]. The replication of $\mathrm{CoVs}$ is inhibited by addition of drugs in the early-secretory phase or by addition of RNAi [77].

\section{Focus on SARS-CoV-2}

Genome of this lethal virus has been isolated; a total of 120 whole genome sequences of SARS-CoV-2 could be downloaded from the GISAID database as depicted in Fig. 1 (https://www.gisaid.org/CoV2020/). Sequences that likely had spurious mutations resulting from sequencing errors were indicated in the comment field of the GISAID data. Its genome is a +ssRNA virus having 29,903 bp length with $3^{\prime}$ poly A tail and 5' cap. GenBank: MN908947.3; Locus MN908947 (https://www. ncbi.nlm.nih.gov/nuccore/MN908947), having 38 aa protein sequence; Locus QHI42199 (https://www.ncbi. nlm.nih.gov/protein/QHI42199.1). The genome of the SARS-CoV-2 reportedly is over $80 \%$ identical to the 


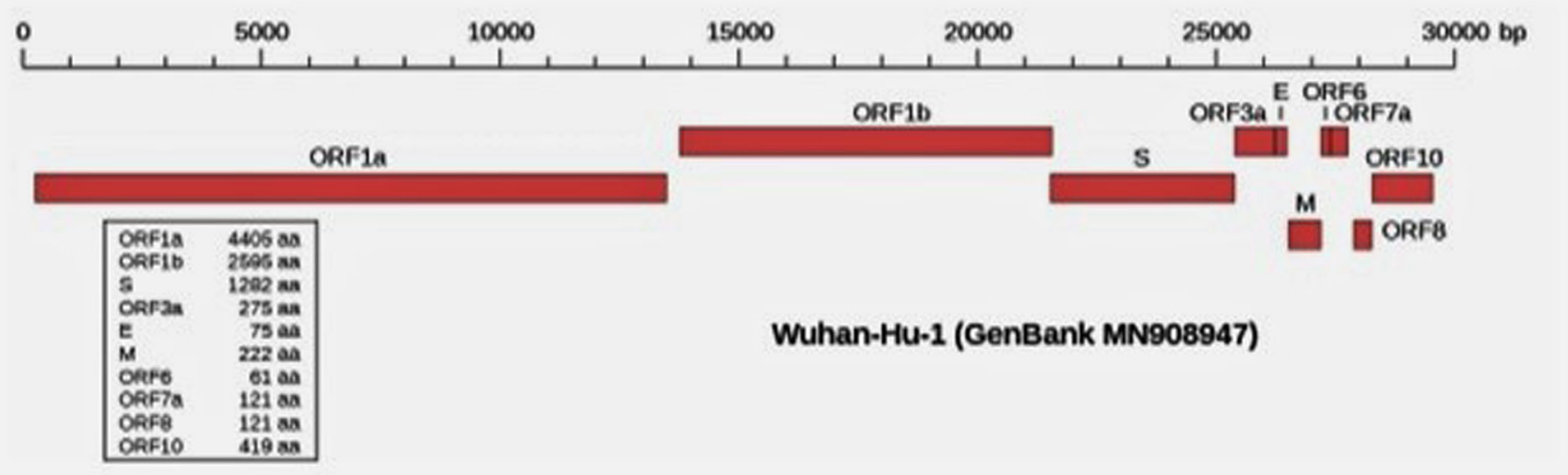

Fig. 1 Representative picture of 30,473 bp length RNA of Wuhan virus (NCBI Genome ID MN908947) [Reprinted from GISAID EpiFlu ${ }^{\mathrm{TM}}$ Database on signing the GISAID EpiFlu ${ }^{\mathrm{TM}}$ Database Access Agreement with proper permission]

previous SARS-like bat $\mathrm{CoV}$, and according to the evolutionary tree, SARS-CoV-2 lies close to SARS-CoV. The $O R F 1 A B$ is the largest gene in SARS-CoV-2 which encodes the PP1AB protein and 15 nsps. The ORF1A gene encodes for PP1A protein which also contains $10 \mathrm{nsps}$. Further, the PP1A and PP1AB encoded by the ORF1a/b give rise to viral proteases, papain-like protease (PLpro), and $3 \mathrm{C}$ cleavage-like protease (3CLpro/Mpro), for creating non-structural proteins (RdRp, helicases) [78]. Mpro is a crucial enzyme facilitating viral replication and transcription. Recent studies have indicated notable variations in SARS-CoV and SARS-CoV-2 such as the absence of $8 \mathrm{a}$ protein and fluctuation in the number of amino acids in $8 \mathrm{~b}$ and $3 \mathrm{c}$ protein in SARS-CoV-2 [79, 80]. Spike glycoprotein of the SARS-CoV-2 has reportedly modified via homologous recombination; it is a mixture of bat SARS$\mathrm{CoV}$ and a not known beta-CoV [81].

\section{Coronavirus Binding and Entry into Host Cells}

Attachment and entry of CoVs into host cells is mediated by "S" protein on outer surface of CoVs. S protein has two domains: S1 and S2 [82]. Within S1 domain, receptor-binding domain (RBD), located at the C-terminus in SARS-CoV and MERS-CoV, mediates binding to the associated host cell receptor, while the $\mathrm{S} 2$ domain brings about the merger between viral and host cell membranes through endosomal pathway, leading to the entry of the viral genome into the cytoplasm of host cell. The virus may infect multiple hosts as the receptorbinding domain (RBD) is loosely attached to it [83, 84]. CoVs mostly identify carbohydrates or amino peptidases as a key receptor for entry to human cells [85]. The mechanism of entry of $\mathrm{CoV}$ in host cell is governed by cellular proteases including human airway trypsin-like protease (HAT), cathepsins, and transmembrane protease serine 2 (TMPRSS2) which cleave spike protein and start further infiltration [86].
Varied CoVs bind to diverse receptors on host cells. MERS-CoV binds to dipeptidyl-peptidase 4 (DPP4, also known as CD26) receptor. Human angiotensin-converting enzyme 2 (hACE2), a zinc-dependent carboxypeptidase, responsible for regulating blood pressure, also acts as a receptor of entry for SARS-CoV, HCoV-NL63, and SARS-CoV-2 [87-89]. The critical lysine 31 residue on the hACE2 receptor recognizes glutamine 394 residues in the RBD region of SARS-CoV-2 [90]. Comprehensive pathogenic mechanism of SARS-CoV-2 is depicted in Fig. 2 [91]. Current studies have indicated $74 \%$ homology between amino acid sequence of RBD of SARS-CoV-2 and SARS-CoV [92] and notable variations between SARS-CoV and SARS-CoV-2 such as the absence of $8 \mathrm{a}$ protein and variation in the number of amino acids in $8 \mathrm{~b}$ and 3c protein in SARS-CoV-2 [93]. As per a recent study, S protein of SARS-CoV-2 has higher affinity to ACE2 receptor as compared with $\mathrm{S}$ protein of SARS$\mathrm{CoV}$ which might be attributed to the N501T mutation in spike protein of SARS-CoV-2.

The spike protein of SARS-CoV-2 binds to hACE2 which is highly expressed in the lungs and heart. Studies suggest that there is an elevation in angiotensin II in COVID-19 patients which advocates that binding of COVID-19 to ACE2 leads to enhanced conversion of angiotensin II from angiotensin I through the renin-angiotensin-aldosterone system (RAAS) thereby increasing cardio-myocyte hypertrophy and high blood pressure leading to myocardial injury, myocarditis, and cardiac arrhythmias [94]. In case of diabetics, there is an altered production of cytokine, impaired $\mathrm{T}$ cell-mediated immune response, inhibition of neutrophil chemotaxis, ineffective microbial clearance, and phagocytic cell dysfunction which together with the entry of coronavirus into host pneumocytes mediated by ACE2 receptor adds to the severity of COVID-19 in patients with diabetes mellitus. So, ACE2 may play a key role in the severity of COVID-19 infection in diabetic patients [94]. 


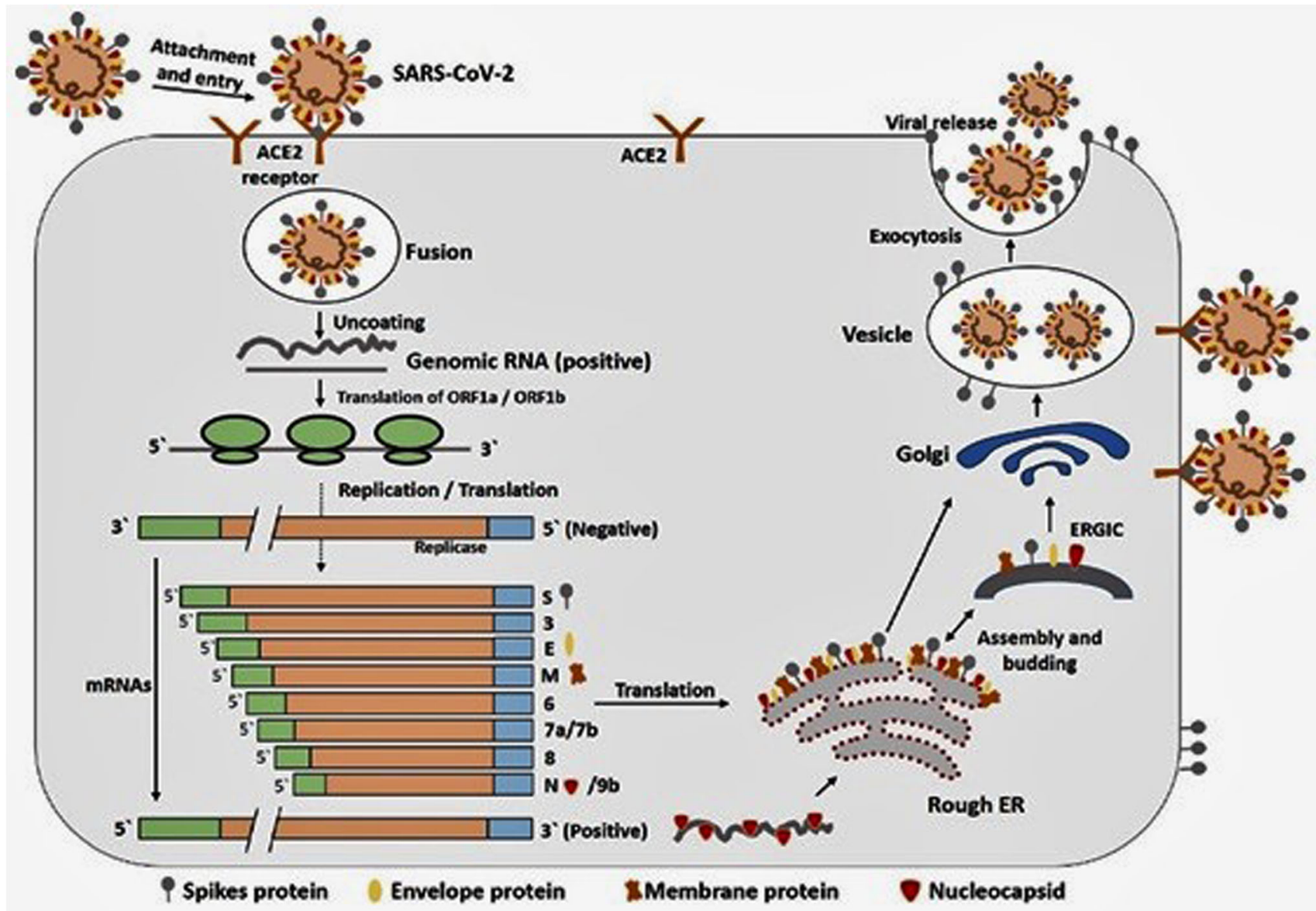

Fig. 2 The life cycle of SARS-CoV-2 in host cells [Reprinted from J.Adv. Res., vol. no. 24, Muhammad AS, Suliman K, Abeer K, Nadia B, Rabeea S, COVID-19 infection: Origin, transmission, and characteristics of human coronaviruses, page no. 91-98, 2020, with permission from Elsevier]

\section{The Coronavirus-Human Interactome}

X-ray crystallography has determined the crystal structures of CoV-human interactomes to fully understand the initial step of infection at molecular level. For the first time, crystalline structure for HCoV-NL63 S1-CTD complexed with human ACE2 was discovered followed by SARS-CoV S1-CTD complexed with ACE2, displaying common receptors $[95,96]$ which was followed by MERS-CoV S1-CTD complexed with human DPP4 [97]. Overall binding mode of ACE2 with SARS-CoV-2-RBD is nearly identical to that of the SARS-CoV-RBD as per the recent elucidation of their crystal structure. There are amino acid residues in RBD of SARS-Co-V, majority of which are highly conserved, or share alike side chain properties with RBD of SARS$\mathrm{CoV}$. Crystal structure of SARS-CoV-2-RBD complexed with ACE2 is available at protein data bank (PDB) [98].

\section{Clinical Research Strategies to Combat COVID-19: Targets to Focus upon}

Presently, no registered antiviral drug for use in patients with COVID-19 is there. On top of it, there is no efficient vaccine available for COVID-19 in humans. The standard of care is "Supportive" and includes drugs like protease inhibitors (lopinavir/ritonavir; darunavir + ritonavir; darunavir/ cobicistat); chloroquine or hydroxychloroquine; tocilizumab, monoclonal antibody against chimeric antigen receptor $\mathrm{T}$ cells; nucleotide inhibitor like remdesivir (a broad-spectrum antiviral); methylprednisolone $20 \mathrm{mg} \times 2 /$ day; and antibiotic therapy using third-generation cephalosporin, clarithromycin, or azithromycin or alternatively fluoroquinolones in case of secondary bacterial infections [99].

A crucial need for a clinical research and therapeutic strategy to counteract this epidemiological outbreak remains. We have no empirical enveloped cure or vaccine for this potentially fatal disease; coordinated international efforts for developing therapeutics and vaccines for SARS-CoV-2 are needed. Although several clinical trials are currently underway to test possible therapies, current response to the COVID-19 outbreak has been largely limited to monitoring/containment. Various biotechnological, molecular tools, and advances in bioinformatics have been instrumental in making available details related to the genomics and proteomics of this virus. Some light has been shed on genetic features, molecular 
constituents, and mechanisms of infection. Armed with this information research is progressing at a rapid pace to develop therapeutic strategies, neutralizing antibodies and vaccines to address this disease COVID-19 which has spread as a pandemic of mammoth proportions. A wide variety of therapeutic options are being evaluated in an earnest attempt to find a cure. A drug, from time of its inception to qualifying all three phases of clinical trials, can take years to reach market; nevertheless, coordinated international efforts and adequate funding can make drugs against COVID-19 available within a record time. Bioinformatics and in silico drug modelling, a boon for speedy drug development, are being exploited. Recent in silico master regulator analysis has shed light on SARS-CoV-2/human interactome detailing the host receptor recognition. Features of the human interactome most affected by the infection including apoptotic and mitochondrial mechanisms and downregulation of the $\mathrm{ACE} 2$ protein receptor have been propounded [100].

There is an upregulation of ACE2 in diabetes and hypertension as they are being treated by ACE inhibitors and angiotensin II type-I receptor blockers (ARBs). ACE2 is also increased by drugs such as thiazolidinediones and ibuprofen. Consequently, the increased expression of ACE2 would facilitate infection with COVID-19 and increase the risk of developing severe fatal COVID-19 viral infection. A further aspect that should be investigated is the genetic predisposition for an increased risk of SARS-CoV-2 infection, which might be due to ACE2 polymorphisms that have been linked to diabetes mellitus, cerebral stroke, and hypertension, specifically in Asian populations. Summarizing this information, the sensitivity of an individual might result from a combination of both therapy and ACE2 polymorphism [101].

Expectedly, development of neutralizing antibodies may take less time due to their speedy trials and high specificity, as a prompt option repurposing of broad spectrum antiviral agents and their combinations is being frantically evaluated.

\section{Conclusions}

Since its emergence, SARS-CoV-2 has drawn well-deserved attention. It led to a pandemic that has shocked and devastated the human world, shattering its economy-massive economic recession is predicted. It is likely that these coronaviruses will continue to emerge and evolve, causing both human and veterinary outbreaks due to their ability to recombine, mutate, and infect multiple species and cell types, including humans. The future of human CoV outbreaks will depend not only on how the viruses will evolve but also on the development of efficient prevention, treatment strategies, and our preparedness to deal with them. Priority funding for research on mechanistic basis of transmission of coronaviruses from one species to other, their reservoirs, zoonotic diseases, possible role of environmental changes, and pollution in leading to such epidemics is needed to face the imminent challenge of such repeated outbreaks. Very rapid and efficient human-to-human transmission is confirmed which is of immense concern necessitating speedy development of therapeutic modalities. Neutralizing antibodies and vaccines could play significant roles in controlling COVID-19. Studies on humancoronavirus interactome developing suitable therapeutic agents and vaccines are needed. Research at accelerated pace is needed to translate into therapies and vaccines. Hopefully, lessons from handling this outbreak will allow us to be better prepared in the future - the viruses can keep coming.

Acknowledgements We acknowledge all the patients who have been infected with SARS-CoV-2 and all the scientists working on COVID19 management.

Authors' Contributions Not applicable.

Data Availability Not applicable.

\section{Compliance with Ethical Standards}

Conflict of Interest The authors declare that they have no conflict of interest.

Ethical Approval Not applicable.

Consent to Participate Not applicable.

Consent for Publication All authors have given their consent for publication.

Code Availability Not applicable.

\section{References}

1. Bradburne AF, Tyrrell DAJ. Coronaviruses of man. Prog Med Virol. 1971;13:373-403.

2. Woo PC, Lau SK, Lam CS, Lau CC, Tsang AK, Lau JH, et al. Discovery of seven novel mammalian and avian coronaviruses in the genus deltacoronavirus supports bat coronaviruses as the gene source of alphacoronavirus and betacoronavirus and avian coronaviruses as the gene source of gammacoronavirus and deltacoronavirus. J Virol. 2012;86:3995-4008.

3. Malcolm RM. Occurrence and frequency of coronavirus infections in humans as determined by enzyme-linked immunosorbent assay. Infect Immun. 1982;14:419-23.

4. Van der Hoek L. Human coronaviruses: what do they cause? Antivir Ther. 2007;12:651-8.

5. Rose RM, Pinkston P, O'Donnell C, Jensen WA. Viral infection of the lower respiratory tract. Clin Chest Med. 1987;8:405-18.

6. Drosten C, Gunther S, Preiser W, van der Werf S, Brodt HR, et al. Identification of a novel coronavirus in patients with severe acute respiratory syndrome. N Engl J Med. 2003;348:1967-76.

7. Peiris JS, Guan Y, Yuen KY. Severe acute respiratory syndrome. Nat Med. 2004;10:S88-97. 
8. Zaki AM, van Boheemen S, Bestebroer TM, Osterhaus AD, Fouchier RA. Isolation of a novel coronavirus from a man with pneumonia in Saudi Arabia. N Engl J Med. 2012;367:1814-20.

9. Guery B, Poissy J, el Mansouf L, Séjourné C, et al. Clinical features and viral diagnosis of two cases of infection with Middle East respiratory syndrome coronavirus: a report of nosocomial transmission. Lancet. 2013;381:2265-72.

10. Wu F, Zhao S, Yu B, Chen Y, Wang W, Song Z, et al. A new coronavirus associated with human respiratory disease in China. Nature. 2020. https://doi.org/10.1038/s41586-020-2008-3.

11. Zhou P, Yang X, Wang X, Hu B, Zhang L, Zhang W, et al. A pneumonia outbreak associated with a new coronavirus of probable bat origin. Nature. 2020. https://doi.org/10.1038/s41586-0202012-7.

12. Wang C, Horby PW, Hayden FG, Gao GF. A novel coronavirus outbreak of global health concern. Lancet. 2020;395:470-3.

13. Ashour HM, Walid FE, Rahman MM, Hatem AE. Pathogens. 2020;186:1-15. https://doi.org/10.3390/pathogens9030186.

14. Zhong N. Management and prevention of SARS in China. Philos Trans R Soc Lond Ser B Biol Sci. 2004;359:1115-6.

15. Jiang G, Christine K. Pathology and pathogenesis of severe acute respiratory syndrome. Am J Pathol. 2007;170:1136- 47.

16. van den Brand JMA, Smits SL, Haagmans BL. Pathogenesis of Middle East respiratory syndrome coronavirus. J Pathol. 2015;235:175-84.

17. WHO. Middle East respiratory syndrome coronavirus (MERSCoV). https://www.who.int/csr/don/12-march-2020-mers-qatar/ en.

18. World-Health-Organization Statement on the second meeting of the International Health Regulations. Emergency Committee regarding the outbreak of novel coronavirus (2019-nCoV). 2005. Available online: https://www.who.int/news-room/detail/30-012020-statement-on-the-second-meeting-of-the-internationalhealth-regulations-(2005)-emergency-committee-regarding-theoutbreak-of-novel-coronavirus-(2019-ncov).

19. Centers-of-Disease-Control-and-Prevention Confirmed 2019$\mathrm{nCoV}$ cases globally. Available online: https://www.cdc.gov/ coronavirus/2019-ncov/locations-confirmed-cases.html.

20. European Centre for Disease Prevention and Control data. Geographical distribution of 2019-nCov cases. Available online: (https://www.ecdc.europa.eu/en/geographical-distribution-2019ncov-cases) (accessed on 05 February 2020).

21. Coronavirus Outbreak. Available at: https://www.worldometers. Info/coronavirus/ Accessed 23 Feb 2020.

22. Xinhua. China's CDC detects a large number of new coronaviruses in the South China seafood market in Wuhan. Available at: https://www.xinhuanet.com/2020-01/27/c 1125504355.htm. Accessed 20 Feb 2020.

23. Cheng ZJ, Shan J. Novel coronavirus: where we are and what we know. Infection. 2019;2020:1-9. https://doi.org/10.1007/s1501002001401-y.

24. Gralinski L, Menachery V. Return of the coronavirus. Viruses. 2020;12:135-40.

25. Huang C, Wang Y, Li X, et al. Clinical features of patients infected with 2019 novel coronavirus in Wuhan, China. Lancet. 2020;395:497-506.

26. Hui DS, Azhar EI, Madani TA, Ntoumi F, Kock R, Dar O, et al. The continuing 2019-nCoV epidemic threat of novel coronaviruses to global health -the latest 2019 novel coronavirus outbreak in Wuhan, China. Int J Infect Dis. 2020;91:264-6.

27. Chaolin H, Yeming W, Li X, Lili R, Jianping Z, Yi H, et al. Clinical features of patients infected with 2019 novel coronavirus in Wuhan, China. Lancet. 2020. https://doi.org/10.1016/S01406736(20)30183-5.

28. Kai D, Bende L, Cesheng L, Huajun Z, Ting Y, Jieming Q, et al. Effectiveness of convalescent plasma therapy in severe COVID-
19 patients. PNAS. 2020;117:9490-6. https://doi.org/10.1073/ pnas.2004168117.

29. Chen N, Zhou M, Dong X, Qu J, Gong F, Han Y, et al. Epidemiological and clinical characteristics of 99 cases of 2019 novel coronavirus pneumonia in Wuhan, China: a descriptive study. Lancet. 2020. https://doi.org/10.1016/S01406736(20) 30211-7.

30. WHO. Emergencies preparedness, response. Pneumonia of unknown origin - China. Disease outbreak news. http://www.who. int/csr/don/12january2020novelcoronaviruschina/en/www.who. int/csr/don/12january-2020-novel-coronavirus-china/en/.

31. Chen Z, Zhang W, Lu Y, et al. From SARS-CoV to Wuhan $2019 \mathrm{nCoV}$ outbreak: similarity of early epidemic and prediction of future trends. Cell-Host-Microbe-D-20-00063. 2020. https:// doi.org/10.2139/ssrn.3528722.

32. Jasper FWC, Shuofeng Y, Kin HK, Kelvin KW, et al. A familial cluster of pneumonia associated with the 2019 novel coronavirus indicating personto-person transmission: a study of a family cluster. Lancet. 2020;395:514-23.

33. Arabi YM, Arifi AA, Balkhy HH, et al. Clinical course and outcomes of critically ill patients with Middle East respiratory syndrome coronavirus infection. Ann Intern Med. 2014;160:389-97.

34. Na Z, Dingyu Z, Wenling W, Li X, Bo Y, Jingdong S, et al. A novel coronavirus from patients with pneumonia in China. $\mathrm{N}$ Engl J Med. 2020;382:727-33. https://doi.org/10.1056/ NEJMoa2001017.

35. Puja M, McAuley DF, Michael B, Emilie S, et al. COVID-19: consider cytokine storm syndromes and immunosuppression. Lancet. 2020;395:1033-4.

36. Litao Z, Xinsheng Y, Qingkun F, Haiyan L, Xintian L, Zejin L, et al. D-dimer levels on admission to predict in-hospital mortality in patients with Covid-19. J Thrombosis Hemostasis. 2020. https://doi.org/10.1111/jth.14859.

37. Chung M, Bernheim A, Mei X, Zhang N, Huang M, Zeng X, et al. CT imaging features of 2019 novel coronavirus (2019-nCoV). Radiology. 2020;04:200-30.

38. Wang D, Hu B, Hu C, Zhu F, Liu X, Zhang J, et al. Clinical characteristics of 138 hospitalized patients with 2019 novel coronavirus-infected pneumonia in Wuhan, China. JAMA. 2020; http://www.ncbi.nlm.nih.gov/ pubmed/32031570.

39. Zhou F, Yu T, Du R, et al. Clinical course and risk factors for mortality of adult in patients with COVID-19 in Wuhan, China: a retrospective cohort study. Lancet. 2020. https://doi.org/10.1016/ S0140-6736(20)30566-3.

40. Zhang JJ, Dong X, Cao YY, et al. Clinical characteristics of 140 patients infected by SARS-CoV-2 in Wuhan, China. Allergy. 2020. https://doi.org/10.1111/all.14238.

41. Liu W, Tao ZW, Lei W, et al. Analysis of factors associated with disease outcomes in hospitalised patients with 2019 novel coronavirus disease. Chin Med J. 2020. https://doi.org/10.1097/CM9. 0000000000000775 .

42. Khachfe H, Chahrour M, Sammouri J, Sahlab H, Makki B, Fares M. An epidemiological study on COVID-19: a rapidly spreading disease. Cureus. 2020;12:e7313. https://doi.org/10.7759/cureus. 7313.

43. Milek J, Blicharz-Domanska K. Coronaviruses in avian speciesreview with focus on epidemiology and diagnosis in wild birds. J Vet Res. 2018;62:249-55.

44. Reusken CB, Haagmans BL, Müller MA, Gutierrez C, Godeke GJ, et al. Middle East respiratory syndrome coronavirus neutralising serum antibodies in dromedary camels: a comparative serological study. Lancet Infect Dis. 2013;13:859-66. https://doi. org/10.1016/S1473-3099(13)70164-6.

45. Lau SK, Woo PC, Li KS, Huang Y, Tsoi HW, Wong BH, et al. Severe acute respiratory syndrome coronavirus-like virus in 
Chinese horseshoe bats. Proc Natl Acad Sci U S A. 2005;102: 14040-5.

46. Forni D, Cagliani R, Clerici M, Sironi M. Molecular evolution of human coronavirus genomes. Trends Microbiol. 2017;25:35-48.

47. Su S, Wong G, Shi W, Liu J, Lai ACK, Zhou J, et al. Epidemiology, genetic recombination, and pathogenesis of coronaviruses. Trends Microbiol. 2016;24:490-502.

48. Zhong NS, Zheng BJ, Li YM, Poon LLM, et al. Epidemiology and cause of severe acute respiratory syndrome (SARS) in Guangdong, People's Republic of China, in February. Lancet. 2003;362:1353-8.

49. Zi-Wei Y, Shuofeng Y, Kit-San Y, Sin-Yee F, Chi-Ping C, DongYan J. Zoonotic origins of human coronaviruses. Int J Biol Sci. 2020;16(10):1686-97.

50. Andersen KG, Rambaut A, Lipkin WI, et al. The proximal origin of SARS-CoV-2. Nat Med. 2020;26:450-2. https://doi.org/10. 1038/s41591-020-0820-9.

51. Lau SKP, Luk HKH, Wong ACP, Li KSM, Zhu L, He Z, et al. Possible bat origin of severe acute respiratory syndrome coronavirus 2. Emerg Infect Dis. 2020. https://doi.org/10.3201/eid2607. 200092.

52. Webster RG. Wet markets-a continuing source of severe acute respiratory syndrome and influenza? Lancet. 2004;363:234-6.

53. Muhammad AS, Suliman K, Abeer K, Nadia B, Rabeea S. COVID-19 infection: origin, transmission, and characteristics of human coronaviruses. J Adv Res. 2020;24:91-8.

54. $\mathrm{Hu} \mathrm{B}, \mathrm{Ge} \mathrm{X}$, Wang $\mathrm{L}$, et al. Bat origin of human coronaviruses. Virol J. 2015;12:221. https://doi.org/10.1186/s12985-015-0422-1.

55. Guo Y, Cao Q, Hong Z, et al. The origin, transmission and clinical therapies on coronavirus disease 2019 (COVID-19) outbreak - an update on the status. Mil Med Res. 2020;7:11. https://doi.org/10. 1186/s40779-020-00240-0.

56. Luk HKH, Li X, Fung J, Lau SK, Woo PC. Molecular epidemiology, evolution and phylogeny of SARS coronavirus. Infect Genet Evol. 2019;71:21-30.

57. World-Health-Organization Coronavirus disease (COVID-19) outbreak. Available online: https://www.who.int/emergencies/ diseases/novel-coronavirus-2019.

58. Lim YX, Ng YL, Tam JP, Liu DX. Human Coronaviruses: a review of virus-host interactions. Diseases. 2016;4:26. https:// doi.org/10.3390/diseases4030026.

59. Bryony A, Jones DG, Richard K, Silvia A, Jonathan R, et al. Zoonosis emergence linked to agricultural intensification and environmental change. PNAS. 2013;110:8399-404. https://doi.org/ 10.1073/pnas. 1208059110.

60. Satesh B, Calum NLM. Zoonoses and one health: a review of the literature. J Parasitol Res. 2014;14:874345. https://doi.org/10. 1155/2014/874345.

61. Bingzheng S, Li C, Lu Z, Mengke Z, Jing L, Jie W, et al. Wuchang Fangcang Shelter Hospital: practices, experiences, and lessons learned in controlling COVID-19. SN Compr Clin Med. 2020. https://doi.org/10.1007/s42399-020-00382-1.

62. Barcena M, Oostergetel GT, Bartelink W, Faas FG, Verkleij A, Rottier PJ, et al. Cryo-electron tomography of mouse hepatitis virus: insights into the structure of the coronavirion. Proc Natl Acad Sci U S A. 2009;106:582-7.

63. Masters PS. The molecular biology of coronaviruses. Adv Virus Res. 2006;66:193-292.

64. Lai MM. Coronavirus: organization, replication and expression of genome. Annu Rev Microbiol. 1990;44:303-33.

65. Thiel V, Ivanov KA, Putics A, Hertzig T, Schelle B, et al. Mechanisms and enzymes involved in SARS coronavirus genome expression. J Gen Virol. 2003;84:2305-15.

66. Kirchdoerfer RN, Cottrell CA, Wang N, Pallesen J, Yassine HM, Turner HL, et al. Pre-fusion structure of a human coronavirus spike protein. Nature. 2016;531:118-21.
67. Siu YL, Teoh KT, Lo J, Chan CM, Kien F, et al. The M, E, and N structural proteins of the severe acute respiratory syndrome coronavirus are required for efficient assembly, trafficking, and release of virus-like particles. J Virol. 2008;82:11318-30.

68. Münz M, Hein J, Biggin PC. The role of flexibility and conformational selection in the binding promiscuity of PDZ domains. PLoS Comput Biol. 2012;8:e1002749.

69. Lu R, Zhao X, Li J, Niu P, Yang B, Wu H, et al. Genomic characterisation and epidemiology of 2019 novel coronavirus: implications for virus origins and receptor binding. Lancet. 2020. https://doi.org/10.1016/S0140-6736(20)30251-8.

70. Eifart P, Ludwig K, Bottcher C, de Haan CA, Rottier PJ, Korte T, et al. Role of endocytosis and low $\mathrm{pH}$ in murine hepatitis virus strain A59 cell entry. J Virol. 2020. https://doi.org/10.1128/JVI. 00725-07.

71. Baric RS, Yount B. Subgenomic negative-strand RNA function during mouse hepatitis virus infection. J Virol. 2000;74:4039-46.

72. Sawicki SG, Sawicki DL, Siddell SG. A contemporary view of coronavirus transcription. J Virol. 2007;81:20-9.

73. Farooq R, Majid S, Hanif A, Qureshi W. Current insights into the genomics of novel coronavirus: SARS-Cov-2. EC Clin Med Case Rep. 2020;3:3-11.

74. Fehr AR, Perlman S. Coronaviruses: An overview of their replication and pathogenesis. Methods Mol Biol. 2015;1282:1-23.

75. Denison MR, Zoltick PW, Hughes SA, Giangreco B, Olson AL, Perlman S, et al. Intracellular processing of the N-terminal ORF 1a proteins of the coronavirus MHV-A59 requires multiple proteolytic events. Virology. 1992;189:274-84.

76. Knoops K, Kikkert M, Worm SH, Zevenhoven-Dobbe JC, van der MY, Koster AJ, et al. SARS-coronavirus replication is supported by a reticulovesicular network of modified endoplasmic reticulum. PLoS Biol. 2008;6:e226.

77. Quadeer AA, Louie RHY, McKay MR. Identifying immunologically-vulnerable regions of the HCV E2glycoprotein and broadly neutralizing antibodies that target them. Nat Commun. 2019;10:2073.

78. Zumla A, Chan JFW, Azhar EI, Hui DSC, Yuen KY. Coronaviruses: drug discovery and therapeutic options. Nat Rev Drug Discov. 2016;15:327.

79. Dai W, Zhang B, Su H, Li J, Zhao Y, Xie X, et al. Structure-based design of antiviral drug candidates targeting the SARS-CoV-2 main protease. Science. 2020;80:eabb4489.

80. Chen Y, Liu Q, Guo D. Emerging coronaviruses: genome structure, replication, and pathogenesis. J Med Virol. 2020;92:418-23. https://doi.org/10.1002/jmv.25681.

81. Li B, Si HR, Zhu Y, Yang XL, Anderson DE, Shi ZL, et al. Discovery of bat coronaviruses through surveillance and probe capture-based next-generation sequencing. mSphere. 2020. https://doi.org/10.1128/mSphere.00807-19.

82. Hoffmann M, Kleine-Weber H, Pohlmann SA. Multibasic cleavage site in the spike protein of SARS-CoV-2 is essential for infection of human lung cells. Mol Cell. 2020;78:779-84. https://doi. org/10.1016/j.molcel.2020.04.022.

83. Li F, Li W, Farzan M, Harrison SC. Structure of SARS coronavirus spike receptor binding domain complexed with the receptor. Science. 2005;309:1864-8.

84. Wang N, Shi X, Jiang L, Zhang S, Wang D, et al. Structure of MERS-CoV spike receptor-binding domain complexed with human receptor DPP4. Cell Res. 2013;23:986-93.

85. Dove A. The bittersweet promise of glycobiology. Nat Biotechnol. 2001;19:913-7. https://doi.org/10.1038/nbt1001913.

86. Hoffmann M, Kleine-Weber H, Kruger N, Muller M, Drosten C, Pohlmann S. The novel coronavirus2019 (2019-nCoV) uses the SARS-coronavirus receptor ACE2 and the cellular protease 
TMPRSS2 for entry into target cells. BioRxiv. 2020. https://doi. org/10.1101/2020.01.31.929042.

87. Li W, Moore MJ, Vasilieva N, Sui J, Wong SK, Berne MA, et al. Angiotensin-converting enzyme 2 is a functional receptor for the SARS coronavirus. Nature. 2003;426:450-4.

88. Hofmann H, Pyrc K, van der Hoek L, Geier M, Berkhout B, Pohlmann S. Human coronavirus NL63employs the severe acute respiratory syndrome coronavirus receptor for cellular entry. Proc Natl Acad Sci U S A. 2005;102:7988-93.

89. Keidar S, Kaplan M, Gamliel-Lazarovich A. ACE2 of the heart: from angiotensin I to angiotensin (1-7). Cardiovasc Res. 2007;73: 463-9. https://doi.org/10.1016/j.cardio.res.2006.09.006.

90. Klausegger A, Strobl B, Regl G, Kaser A, Luytjes W, Vlasak R. Identification of a coronavirus hemagglutinin-esterase with a substrate specificity different from those of influenza $\mathrm{C}$ virus and bovine coronavirus. J Virol. 1999;73:3737-43.

91. Shereen MA, Khan S, Kazmi A, Bashir N, et al. COVID-19 infection: origin, transmission, and characteristics of human coronaviruses. J Adv Res. 2020;24:91-8.

92. Ou X, Liu Y, Lei X, Li P, Mi D, Lili R, et al. Nat Commun. 2020;11:1620. https://doi.org/10.1038/s41467-020-15562-9.

93. Wu A, Peng Y, Huang B, Ding X, Wang X, Niu P, et al. Genome composition and divergence of the novel coronavirus (2019$\mathrm{nCoV}$ ) originating in China. Cell Host Microbe. 2020;27:325-8. https://doi.org/10.1016/j.chom.2020.02.001.

94. Sourav R, Tanoy M, Sujan B. The Association of Cardiovascular Diseases and Diabetes Mellitus with COVID-19 (SARS-CoV-2) and their possible mechanisms. SN Compr Clin Med. https://doi. org/10.1007/s42399-020-00376-z.
95. Wu K, Li WB, Peng G, Li F. Crystal structure of NL63 respiratory coronavirus receptor-binding complexed with its human receptor. Proc Natl Acad Sci U S A. 2009;106:19970-4. https://doi.org/10. 1073/pnas.0908837106.

96. Shang J, Ye G, Shi K, et al. Structural basis of receptor recognition by SARS-CoV-2. Nature. 2020;581:221-4. https://doi.org/10. 1038/s41586-020-2179-y.

97. Lu G, Hu Y, Wang Q, Qi J, Gao F, Li Y, et al. Molecular basis of binding between novel human coronavirus MERS-CoV and its receptor CD26. Nature. 2013;500:227-31. https://doi.org/10. 1038/nature12328.

98. Crystal structure of SARS-CoV-2 spike receptor-binding domain bound with ACE. BioRxiv. 2020. https://doi.org/10.1101/2020. 02.19.956235.

99. Alfredo P, Giulia C, Francesca F, Antonio M, Laura T, Alberto S, et al. Clinical management of adult coronavirus infection disease 2019 (COVID-19) positive in the setting of low and medium intensity of care: a short practical review. SN Compr Clin Med. https://doi.org/10.1007/s42399-020-00333-w.

100. Pietro HG, Daniele M, Carmine C, Federico MG. Master regulator analysis of the SARS-CoV-2 /human interactome. J Clin Med. 2020;9:982. https://doi.org/10.3390/jcm9040982.

101. Kalpana P, Venkata RN. COVID-19 outbreak: an update on therapeutic options. SN Compr Clin Med. https://doi.org/10.1007/ s42399-020-00264-6.

Publisher's Note Springer Nature remains neutral with regard to jurisdictional claims in published maps and institutional affiliations. 